\title{
ANTIGENIC PROPERTIES OF NATIVE AND REGENERATED HORSE SERUM ALBUMIN*†
}

By JOHN O. ERICKSON and HANS NEURATH, Ph.D.

(From the Department of Biochemistry, Duke University, School of Medicine, Durham, North Carolina)

(Received for publication, February 15, 1943)

One of the characteristic manifestations of biological activity of proteins resides in their ability to elicit antibody formation. While the activity of certain immune bodies, as well as that of enzymes, or viruses, is known to be destroyed by processes causing protein denaturation, the relation between denaturation and antigenicity is only vaguely understood.

It has been reported that denaturation by heat (1-3), acid and alkali (4-7), ultraviolet irradiation $(8,9)$, or by controlled enzymatic action (10-12) alters the antigenic behavior of proteins. While earlier workers generally agreed that a denatured protein has both reduced antigenicity and altered serological specificity, more recent investigations of photo-oxidized egg albumin (13) and protein films (14) have indicated the possibility that certain kinds of denaturation may take place without any considerable alteration in specificity. The apparently conflicting evidence adduced in these studies may, at least in part, be ascribed to loose definition of the term denaturation.

In a recent analysis of the problem, occurrence of intramolecular changes in a protein have been considered as the main criterion for denaturation (15), thereby excluding processes which result in reversible dissociation or aggregation of native protein molecules, or reactions with groups on the surface of protein molecules which leave their internal structure intact.

Therefore, in order to correlate changes in immunological properties with effects of denaturation, as defined above, it is necessary: (1) to preclude the occurrence of changes in the nature of reactive chemical groupings on the surface of the protein molecule, which have been shown to be important in determining immunological specificity; (2) to carry out the denaturation process in a rigidly controlled fashion; and (3) to deal with proteins, well characterized in both native and denatured state.

In preceding papers of this series (16) it was shown that if the process of denaturation of crystalline horse serum albumin by strong urea solutions is reversed, by dialyzing out the denaturing agent, a protein fraction is obtained

* This work was carried out with the aid of grants from The Rockefeller Foundation, the Lederle Laboratories, Inc., and the Duke University Research Council.

† A preliminary report of the results has already been published in Science, 1942, $96,116$. 
which, although closely resembling the native material in molecular size and shape, is actually in a denatured state. Differences observed in solubility (16), electrophoretic mobility (17), and response to tryptic digestion (18) have led to the conclusion that this "regenerated" protein is devoid of the specific intrinsic configuration of the native molecule. Comparative measurements on native and urea-regenerated horse serum albumin have now been carried out in order to determine the influence of denaturation on antigenic activity and serological specificity. ${ }^{1}$

\section{EXPERIMENTAL}

Preparation of Antigens.-Crystalline horse serum albumin, fraction A, was prepared by the method of Kekwick (19).

Denaturation by $8 \mathrm{~m}$ urea solutions, and regeneration, was effected as described previously (15). The proteins were preserved by desiccation from the frozen state (20) and dissolved as needed.

Method.-The method employed involves injection of equal amounts of native and regenerated protein into two series of rabbits and titrating the antisera with homologous and heterologous antigen.

Immunization.-Seven rabbits, weighing from 2 to 5 kilos, were immunized against native protein by a series of injections into the marginal ear vein, four times a week, over a period of 3 to 4 weeks. The total dose varied from 10 to $35 \mathrm{mg}$. per kilo body weight. Five rabbits were treated similarly with regenerated protein. All proteins were dissolved in saline for injections. 8 to 10 days after the last injection, following a 24 hour fast, the rabbits were bled via the ear vein or the carotid artery, the blood allowed to clot in paraffined tubes, and the clear sera drawn off. Preceding immunization, $10 \mathrm{cc}$. of blood were drawn from the ear vein of each animal and the sera stored for any necessary control analysis.

To determine the effect of reimmunization upon antibody titer, rabbits 10 and 13 were given, 2 weeks later, an equal additional immunizing dose of the same antigen, and the sera collected as before.

Titration of Precipitins.-(1) Precipitin titer was determined by the optimal proportion method of Culbertson (21), using $0.25 \mathrm{cc}$. of whole serum or an appropriate dilution thereof, and $0.25 \mathrm{cc}$. of a series of twofold dilutions of antigen. The antigens were dissolved in Ringer-phosphate solutions of 0.1 ionic strength, $\mathrm{pH}$ 7.4. Precipitates were kept at $37^{\circ} \mathrm{C}$. for 2 to 3 hours and subsequently in the refrigerator overnight. After centrifugation, $0.1 \mathrm{cc}$. portions of the supernatant solution were used in testing for residual antigen or antibody.

(2) The quantitative method of Heidelberger and Kendall (22) was applied to three immune sera, i.e. Nos. 5, 12, and 13, to determine antibody nitrogen and antibody-antigen ratios in the precipitates.

(3) The highly sensitive method of precipitin titration, recently described by Martin (23), was also employed to estimate the antibody content of some of the low titer immune sera.

\footnotetext{
${ }^{1}$ We are indebted to Dr. A. J. Weil of the Lederle Laboratories, Inc., for carrying out a few exploratory immunological experiments.
} 


\section{RESULTS}

Antigenicity.-In Table I, data are given relative to the course of immunization and the resulting antibody titer of the sera.

It may be noted that administration of native horse serum albumin yielded a considerably greater antibody response than that produced by immunization against the regenerated protein. Only in one instance was the antibody titer of an anti-native serum lower than that found for the most potent anti-regenerated serum, (i.e. sera 9 and 5), whereas in the majority of cases, anti-native rabbit sera were considerably stronger than anti-regenerated sera. The mean

TABLE I

\begin{tabular}{|c|c|c|c|c|c|c|c|}
\hline \multirow{3}{*}{ Antiserum } & \multirow{3}{*}{$\underset{\text { antigen }}{\text { Homologous }}$} & \multirow{3}{*}{ Total dose } & \multirow{3}{*}{$\begin{array}{l}\text { Dose per } \\
\text { kg. body } \\
\text { wight }\end{array}$} & \multirow{3}{*}{ Time } & \multicolumn{3}{|c|}{ Antigen combined by $1 \mathrm{cc}$. antiserum } \\
\hline & & & & & \multicolumn{2}{|c|}{ Culbertson } & \multirow{2}{*}{$\begin{array}{c}\text { Heidelber } \\
\text { ger }\end{array}$} \\
\hline & & & & & $\begin{array}{c}\text { Homolo- } \\
\text { gous }\end{array}$ & $\begin{array}{c}\text { Heterolo- } \\
\text { gous }\end{array}$ & \\
\hline & & $m g$. & $m \mathrm{~g}$. & wks. & mg. & $m g$. & $m g$. \\
\hline 2 & Native & 160 & 32 & 5 & 1.9 & 0.4 & \\
\hline 3 & Native & 160 & 30 & 5 & 8.0 & 1.0 & \\
\hline 9 & Native & 60 & 11.5 & 4 & 0.24 & 0.24 & \\
\hline 12 & Native & 40 & 9.5 & 4 & 1.0 & 1.0 & $1.23^{*}$ \\
\hline 15 & Native & 120 & 30 & 4 & 8 & & \\
\hline 16 & Native & 120 & 30 & 4 & 4 & & \\
\hline 17 & Native & 120 & 30 & 4 & 0.5 & 0.5 & \\
\hline 5 & Regenerated & 160 & 35 & 5 & 0.5 & 0.5 & $0.54^{*}$ \\
\hline 6 & Regenerated & 160 & 34 & 5 & 0.13 & 0.13 & \\
\hline \multirow[t]{2}{*}{13} & Regenerated & 40 & 10 & 4 & 0.25 & 0.25 & \\
\hline & & 80 & 20 & 8 & 0.25 & & \\
\hline \multirow[t]{2}{*}{10} & Regenerated & 60 & 12.6 & 4 & 0 & 0 & \\
\hline & & 100 & 21 & 8 & 0 & 0 & \\
\hline 14 & Regenerated & 40 & 9.1 & 4 & 0.12 & 0.12 & $0.19^{*}$ \\
\hline
\end{tabular}

* Homologous antigen.

titer of the former group of sera was 3.8, that of the latter was 0.2 (mg. of antigen combined with $1 \mathrm{cc}$. of serum).

Since the optimal proportion method of Culbertson furnishes no conclusive indication of the actual amount of precipitin that may be present in an immune serum, quantitative measurements of the amount of antibody $\mathrm{N}$ precipitated were also carried out on three representative antisera to native and regenerated serum albumin. The results are given in Table II.

Inspection of the data reveals not only a close agreement between these two methods of titration but also demonstrates an approximately identical combining ratio, $R$, between antibody and antigen, for both native and regenerated protein. Hence the possibility that the observed difference in antigenicity may 
be merely due to differences in the composition of the specific precipitates, may be excluded.

Relation of Immunizing Dose to Precipitin Titer.-It has not been possible to correlate the size of the immunizing dose with the resulting antibody titer. This is borne out by the wide variation in antibody response observed for both groups of sera as well as by the failure of rabbits 10 and 13 to show an increase in antibody titer when subjected to a second course of immunization. It is recognized that extension of these experiments to a considerably larger group

TABLE II

Antibody N Precipitated from Antisera by Varying Amounts of Homologous Antigen

\begin{tabular}{|c|c|c|c|c|c|c|c|}
\hline \multirow{2}{*}{$\begin{array}{c}\text { Antigen } N \\
\text { added }\end{array}$} & \multirow{2}{*}{$\begin{array}{c}\text { Total N } \\
\text { precipitated }\end{array}$} & \multirow{2}{*}{$\begin{array}{l}\text { Antibody } N \\
\text { precipitated }\end{array}$} & \multirow{2}{*}{$\frac{\text { Antibody N }}{\text { Antigen N }}$} & \multicolumn{2}{|c|}{ Supernatants } & \multirow{2}{*}{$\mathrm{R}^{*}$} & \multirow{2}{*}{$\begin{array}{l}\text { Antigen } \\
\text { combined by } \\
1 \text { cc. serum }\end{array}$} \\
\hline & & & & A & $\mathrm{s}$ & & \\
\hline mg. & ms. & mg. & & & & & $m g$. \\
\hline \multicolumn{8}{|c|}{$1 \mathrm{cc}$. of $(1: 1)$ immune serum 5} \\
\hline 0.015 & 0.203 & 0.188 & 12.5 & + & 0 & \multirow{5}{*}{7.9} & \\
\hline 0.022 & 0.257 & 0.235 & 10.7 & 0 & 0 & & \\
\hline 0.029 & 0.272 & 0.243 & 8.4 & 0 & 0 & & \\
\hline 0.037 & 0.318 & 0.281 & 7.6 & 0 & 0 & & 0.54 \\
\hline 0.051 & 0.285 & 0.234 & 4.6 & 0 & + & & \\
\hline \multicolumn{8}{|c|}{$1 \mathrm{cc}$ of immune serum 12} \\
\hline 0.071 & 1.015 & 0.944 & 13.3 & + & 0 & \multirow{4}{*}{8.33} & \multirow{4}{*}{1.23} \\
\hline 0.132 & 1.52 & 1.388 & 10.6 & + & 0 & & \\
\hline 0.142 & 1.515 & 1.373 & 9.7 & 0 & 0 & & \\
\hline 0.180 & 1.63 & 1.45 & 8.1 & 0 & + & & \\
\hline \multicolumn{8}{|c|}{4 cc. of immune serum 14} \\
\hline 0.0312 & 0.532 & 0.501 & 16.1 & + & 0 & & \\
\hline 0.046 & 0.734 & 0.687 & 14.8 & + & 0 & & \\
\hline 0.062 & 0.893 & 0.831 & 13.4 & + & 0 & & \\
\hline 0.176 & 1.68 & 1.51 & 8.6 & 0 & 0 & 9.35 & 0.19 \\
\hline
\end{tabular}

* Ratio of antibody to antigen at equivalence.

$\mathrm{A}=$ antibody. $\mathrm{S}=$ antigen.

of animals will be required to establish any such correlation and also to establish a statistical mean value for the actual titers of anti-native and anti-regenerated rabbit sera. The data as obtained here, however, serve to illustrate the existence of a statistically significant difference between these two antigens in the antibody response they are able to elicit.

Immunological Specificity.-Cross reactions of the sera with heterologous antigen established in all but two cases (sera 2 and 3 ) the immunological equivalence of native and regenerated serum albumin. Immunological equivalence has been defined by Marrack (24) as: "Two antigens A and B will be said to be 'equivalent' when the antiserum to $\mathrm{A}$ reacts to the same titer with both $\mathrm{A}$ and 
B, and vice versa." As a further test for the unchanged serological specificity of a denatured protein, serum 12 was titrated with a solution of irreversibly denatured albumin (16); it was found to react with the same titer toward this protein fraction as toward native and regenerated material.

Electrophoresis ${ }^{2}$.- -In an attempt to correlate antibody titer with the quantitative increase in serum globulin, known to occur frequently as a result of immunization (25), electrophoretic analyses were carried out on a number of sera before and after immunization. Measurements were carried out in the Tiselius electrophoresis apparatus, equipped with the cylindrical lens system. The relative distribution of the electrophoretic components was determined by graphical integration of the projected tracings of the individual refractive index gradient curves. Although a consistent increase in the globulin components, particularly in the gamma globulin, was noted, no quantitative correlation between globulin increase and antibody titer was found.

\section{DISCUSSION}

The present investigation yielded two significant findings: (1) a decrease in antigenic activity concomitant to regeneration of crystalline horse serum albumin, and (2) immunological equivalence of native and regenerated protein.

The question may be raised whether the reduced antigenic activity of regenerated albumin may not be merely simulated by the production of non-precipitating antibodies, or else by failure of the antigen to cause complete specific precipitation, as has been observed by Bawden and Kleczkowski (26) for certain heated proteins. While the latter possibility may be ruled out by the observation of immunological equivalence of native and regenerated serum albumin, there is no experimental evidence to substantiate the former. If the non-precipitating antibodies were due to an altered specificity of the regenerated antigen, again immunological equivalence would be unlikely to exist.

Since the regenerated albumin resembled closely the native in molecular size and shape, and differed from it only slightly in electrophoretic properties and in solubility, it is not likely that these physicochemical properties play a major rôle in conferring upon the native protein its antigenic powers. Sources of the observed difference in antigenicity between native and regenerated albumin could be conceivably found in differences in (1) carbohydrate content, (2) resistance to proteolytic fission, and (3) the specific intrinsic configuration of the protein molecules.

As to the first possibility, it may be significant that complex carbohydrates have been found to be the haptenic group of certain bacteria, particularly of

${ }^{2}$ The authors wish to thank Dr. Gerald R. Cooper of the Department of Experimental Surgery, Duke University School of Medicine, for the electrophoretic analyses. 
pneumococci, to which extremely potent rabbit antisera have been obtained. Moreover, Hewitt believes to have shown that a good deal of the antigenicity of horse serum albumin is due to the carbohydrate-rich seroglycoid fraction (27), and recent work on bovine albumin has indeed revealed the carbohydrate-free crystalbumin to be less antigenic than its carbohydrate-containing counterpart (28). However, chemical analysis showed the carbohydrate content of native and regenerated horse serum albumin to be the same ( 1.95 per cent), thereby discounting the possibility of the carbohydrate content as a decisive factor.

According to recent theories, antibodies are modified serum globulins, synthesized in the presence of the antigen (29). Whether the antigen merely initiates the reaction or must be present during synthesis is not known. If its presence were necessary for any length of time, obviously a protein which is readily removed or destroyed will be less apt to affect the synthesis of normal serum globulins and, as a result, will give rise to little or no antibody formation. In a preceding paper of this series (18), it was shown that regenerated horse serum albumin is more susceptible to tryptic hydrolysis than the native protein. Lin, $\mathrm{Wu}$, and Chen (30) found the same to be true for egg albumin denatured by various means. While the problem of the natural proteoly tic activity of plasma or serum is a matter of conjecture, the greater susceptibility of the regenerated horse serum albumin to proteoly tic hydrolysis deserves consideration as a factor influential in rendering it less antigenic.

In contradistinction to these views, TenBroeck (4) and Heilner (31) believe that it is the destruction of the antigen which promotes antibody formation. The possibility must not be overlooked, however, that these workers were dealing with a racemized protein and that the reduction in antigenic activity may be due to unnatural optical activity of their antigen.

The present findings lend support to the third of the aforementioned hypotheses, i.e. that the antigenic activity of this protein resides in the very structural features which are altered or destroyed during the denaturation process. If this hypothesis were correct, then antigenic activity has to be considered as specific a manifestation of biological function as those exhibited by enzymes, viruses, or complement, for instance, for it has been demonstrated convincingly that destruction of the specific configuration of these proteins by denaturation, results in a complete abolishment of their biological activities. Unequivocal proof of such a hypothesis requires further experimentation along the lines indicated in this paper.

The data presented here leave little doubt that the regeneration process did not alter the serological specificity of native horse serum albumin. All but two anti-native rabbit sera reacted with the same titer toward regenerated albumin, and vice versa, every anti-regenerated rabbit serum proved to react equally with regenerated and native horse serum albumin. While these findings appear to 
be contradictory to some of the earlier investigations on native and denatured proteins, it must be realized that there, the products of denaturation were only ill defined chemically, or physicochemically. Rothen and Landsteiner's immunological studies with surface films of proteins, which are prototypes of true denaturation, agree, however, with the present data. These findings, together with Landsteiner's classical research on chemically modified proteins (32), suggest that processes which leave the nature and sequence of amino acid residues in the polypeptide chain of a protein unaffected, have no effect on the serological specificity of the protein.

\section{SUMMARY}

Comparative immunological measurements have been carried out on crystalline horse serum albumin in the native state and after regeneration from $8 \mathrm{M}$ urea solutions. The mean antigenic activity of the regenerated protein has been found to be less than 10 per cent of that of the native, whereas both antigens proved to be immunologically equivalent. The problem of the relation between protein denaturation and immunological activity has been considered and discussed on the basis of known physical and chemical differences between native and denatured protein.

\section{BIBLIOGRAPHY}

1. Salter, A., Guy's Hosp. Rep., 1896, 53, 241.

2. Schmidt, W. A., Biochem. Z., 1908, 14, 294.

3. Furth, J., J. Immunol., 1925, 10, 777.

4. TenBroeck, C., J. Biol. Chem., 1914, 17, 369.

5. Landsteiner, K., and Barron, C., Z. Immunitätsforsch., (Orig.), 1909, 2, 109.

6. MacPherson, C. F. C., and Heidelberger, M., Proc. Soc. Exp. Biol. and Med., $1940,43,646$.

7. Wells, H. G., J. Infect. Dis., 1909, 6, 506.

8. Jonesco-Mihaiesti, C., and Baroni, V., Compt. rend. Soc. biol., 1910, 68, 393.

9. Doerr, R., and Maldavan, J., Wien. klin. Woch., 1911, 23, 555.

10. Weil, A. J., Parfentjev, I., and Bowman, K., J. Immunol., 1938, 35, 399.

11. Pope, C. G., Brit. J. Exp. Path., 1939, 20, 132.

12. Cogill, R., and Fell, N., J. Immunol., 1940, 39, 207.

13. Smetana, H., and Shemin, D., J. Exp. Med., 1941, 73, 223.

14. Rothen, A., and Landsteiner, K., J. Exp. Med., 1942, 76, 437.

15. Neurath, H., Cooper, G. R., and Erickson, J. O., J. Phys. Chem., 1942, 46, 203.

16. Neurath, H., Cooper, G. R., and Erickson, J. O., J. Biol. Chem., 1942, 142, 249.

17. Sharp, D. G., Cooper, G. R., Erickson, J. O., and Neurath, H., J. Biol. Chem., 1942, 144, 139.

18. Bernheim, F., Neurath, H., and Erickson, J. O., J. Biol. Chem., 1942, 144, 259.

19. Kekwick, R. A., Biochem. J., 1938, 32, 552.

20. Taylor, A. R., and Beard, J. W., Science, 1940, 92, 611.

21. Culbertson, J. T., J. Immunol., 1932, 23, 439. 
22. Heidelberger, M., and Kendall, F. E., J. Exp. Med., 1935, 61, 559, 563.

23. Martin, D. S., J. Lab. and Clin. Med., 1943, 28, 870.

24. Marrack, J. R., The chemistry of the antigens and antibodies, London, His Majesty's Stationery Office, 1938, 72.

25. Tiselius, A., and Kabat, E. A., J. Exp. Med., 1939, 67, 119.

26. Bawden, F. C., and Kleczkowski, A., Brit. J. Expt. Path., 1941, 22, 208.

27. Hewitt, L. F., Biochem. J., 1937, 31, 1047.

28. Martin, D. S., Erickson, J. O., and Neurath, H., Fed. Proc., 1943, 2, 66.

29. Pauling, L., J. Am. Chem. Soc., 1940, 62, 2643.

30. Lin, K., Wu, H., and Chen, T., Chinese J. Physiol., 1928, 2, 107.

31. Heilner, E., Z. Biol., 1907, 1, 26.

32. Landsteiner, K., The specificity of serological reactions, Springfield, Illinois, Charles C. Thomas, 1936. 